\title{
Development and evaluation of robust tree biomass equations for rubber tree (Hevea brasiliensis) plantations in India
}

\author{
Biplab Brahma ${ }^{1}$, Gudeta W. Sileshi' ${ }^{2}$ Arun Jyoti Nath ${ }^{1 *}$ and Ashesh Kumar Das ${ }^{1}$
}

\begin{abstract}
Background: In India, rubber (Hevea brasiliensis) plantations cover $\sim 0.8$ million ha of land, emphasizing its significant role in the Earth's carbon dynamics. Therefore, it is important to estimate the biomass stocks of plantations precisely in the context of carbon management. Previous studies in India have focused on development of allometric equations for estimating aboveground biomass (AGB) through harvesting younger trees (up to $14 \mathrm{yr}$ ) only or on studies with small sample sizes without assessing model bias. The objective of this study was to develop biomass estimation models for different tree components in rubber plantations and assess model predictive performance at the stand level.

Methods: A total of 67 trees were harvested from plantations of different ages $(6,15,27$ and $34 \mathrm{yr})$ in North East India and their diameter at $200 \mathrm{~cm}(D)$, height and dry weights of different tree components were recorded. The data were used for evaluation of H-D and biomass estimation models at the stand level.

Results: The Michaelis-Menten function was found to be the most appropriate model for estimating tree height among 10 commonly used H-D models. For estimation of AGB and coarse root biomass, a model that involves tree volume (i.e. $D^{2} H$ ) was found to provide better prediction than either $D$ or $H$ alone or a model that combines $H, D$ and

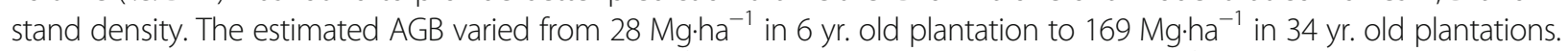

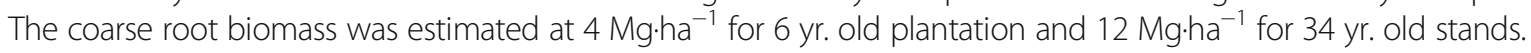

Conclusions: It is concluded that models involving tree volume are more appropriate for regional level biomass estimation than simple power-law models for individual stands. We recommend that the power-law model should not be used for estimation of AGB in plantations at different growth stages because power-law parameters can be biased due to data truncation.
\end{abstract}

Keywords: Aboveground biomass, Data truncation, Michaelis-Menten function, Power-law

\section{Background}

Accurate biomass estimation of plantations and natural forests is a prerequisite for establishing regional carbon inventory datasets. Tree biomass may be estimated through destructive harvesting or non-harvest methods (Brown 1997). In the case of the non-destructively approach available generalized models are often used for estimating biomass in forests, agroforestry and plantation forestry (Brown and Schroeder 1999; Chave et al. 2001; Houghton

\footnotetext{
* Correspondence: arunjyotinath@gmail.com

'Department of Ecology and Environmental Science, Assam University,

Silchar, Assam 788011, India

Full list of author information is available at the end of the article
}

et al. 2001). However, due to variations in plant architectures and complexity in associations of trees, biomass estimation through generalized models is fraught with errors (Ter-Mikaelian and Korzukhin 1997; Shepashenko et al. 1998; Brown and Schroeder 1999; De Oliveira and Mori 1999). Generalized models have often been used without consideration of the tree age or plantation age. Tree age is an important factor that influences biomass accumulation (Fatemi et al. 2011), suggesting the need for age-specific biomass models for precise estimation.

Rubber tree plantations are managed throughout the tropical worlds due to their significant economic value (Fox et al. 2012) and each plantation is managed under 
homogeneous age series up to maximum of $40 \mathrm{yr}$. (Brahma et al. 2016). In India, 0.8 million ha of land is currently under rubber plantation and the annual increase in acreage is 3\% (The Rubber Board 2013). Although rubber plantations cover a vast land area in India, appropriate biomass estimation models are still lacking. The available models were either developed by harvesting younger trees (Chaudhuri et al. 1995; Dey et al. 1996) or limited to a very small sample size (Dey et al. 1996). The need for developing models covering a wide range of tree ages is important because the shape of the relationships between tree variables change along the stage of development. The variations in biomass stocks in rubber plantations with plantation age have been demonstrated (Tang et al. 2009). All these raise concerns about the applicability of available models for future biomass estimation in India. Therefore, the objective of this study was to develop biomass estimation models for different tree components in rubber plantations and assess model predictive performance at the stand level.

\section{Methods}

\section{Study site}

The present study was carried out in Karimganj District of Assam $\left(24^{\circ} 36^{\prime} \mathrm{N}, 92^{\circ} 23^{\prime} \mathrm{E}\right)$, North East India (NEI) within the range of Himalayan foothills and Barak river basins. Karimganj is an administrative district of the State of Assam, which occupies an area of $1809 \mathrm{~km}^{2}$. It is bounded on the Northeast by Cachar District, on the east by Hilakandi, on the south by Mizoram, on the southwest by Tripura State and on the west and northwest by Bangladesh. The edge to edge distance between the selected stands for different ages were measured approximately as $200-300 \mathrm{~m}$. Generally, the soils of the region are classified as the Barak series, which is fine, hyperthermic family of Aeric Endoaquepts (USDA 1998). The soil characteristics of the study site did not vary from stand to stand. Mean annual precipitation of the study area is about $3538 \mathrm{~mm}$, temperature ranges from $13{ }^{\circ} \mathrm{C}$ to $37{ }^{\circ} \mathrm{C}$ with average relative humidity of $93.5 \%$ (Regional Agricultural Research Institute 2013).

\section{Stand selection, sampling and biomass analysis}

The main criterion for selecting the specific plantation was the age of the stand. Age of the plantation was evaluated and confirmed from the official plantation record. Rubber plantations of four different ages, i.e. 6, 15, 27 and 34 yrs., were selected for this study on the basis of the availability of the stands under same age. Ten plots measuring $25 \mathrm{~m} \times 25 \mathrm{~m}$ area were selected randomly from each of the different aged plantations and all trees were counted for estimation of tree density. All the trees within the selected area were counted and measured at circumference at $200 \mathrm{~cm}$ (C200) above the ground to avoid the tapping artefacts. When collecting the latex from rubber trees, tapping on the stems is commonly done between stem heights of 150 and $180 \mathrm{~cm}$. Regular tapping resulted in significant deformations on the stem. Therefore, instead of following the recommended height to measure the stem circumference, here the stem height at $200 \mathrm{~cm}$ was considered. We acknowledge that this can lead to a systematic underestimation of diameter at breast height $(\mathrm{DBH})$. Standard procedures were followed during the circumference measurement of each tree (Husch et al. 2003). The measured C200 values across the ages ranged between 10 and $110 \mathrm{~cm}$, which were further divided into $10 \mathrm{~cm}$ classes. Five to six C200 classes were considered for each stand. Based on the availability of trees in these C200 classes, a total of 67 trees of different ages $(15,19,15$, and 18 for $6,15,27$ and 34 yrs., respectively) were felled. Total height $(H)$ of each harvested tree was measured to use as a covariate in biomass model development. Here the main support to the branches from ground level to the top of the felled tree was considered as stem. In order to avoid the ambiguity of branch and stem at the fork, the higher circumference was considered as the stem. Different tree parts including foliage, branch and stems were separated and fresh weight (fw) in $\mathrm{kg}$ was measured in the field. For belowground biomass, coarse roots $(>2.5 \mathrm{~mm}$ diameter) were extracted from a $1 \mathrm{~m}$ radius with $1 \mathrm{~m}$ depth around the felled tree stem. Fine root biomass could not be estimated due to difficulties in separation of fine roots from the soil. Fresh weights of extracted coarse roots were weighed after carefully removing the soil. Sub-samples of each tree part were taken to the laboratory and subsamples were oven dried at $70{ }^{\circ} \mathrm{C}$ for a minimum of $72 \mathrm{~h}$ or until the constant dry weight was achieved. Fresh weight and dry weight $(\mathrm{dw})$ ratios $\left(R_{\mathrm{dw} / \mathrm{fw}}\right)$ for each plant part were calculated to get their respective total part dry weight $(\mathrm{PDW})$ as $\mathrm{PDW}=\left(R_{\mathrm{dw} / \mathrm{fw}} \times\right.$ fresh weight of the plant part). Total dry weight or total biomass of the tree was estimated by adding all the calculated PDW of that tree.

\section{Biomass model development}

Use of different independent variables for developing biomass models are still a subject of empirical debate (Sileshi 2014). Diameter at breast height $(D)$ and total tree height $(H)$ have been used widely for modelling scaling relationships between tree biomass components, $H$ and $\mathrm{DBH}$ assuming different physical and biological first principles (Sileshi 2014). In this study first we developed the relationship between D200 (here after D) and $H$ as well as biomass components with $D, H$ and stand density (StD). First we explored the appropriateness of a simple power-law relationship between AGB, $D$ and $H$. 
This is because power-law scaling is supported by emergent theories of macroecology and thus recommended in biomass estimation to reduce the ambiguity about allometric relationships (Sileshi 2014, 2015). Initially we also explored the use of stand age as a covariate. However, we found stand age to be inappropriate due statistical complications such as collinearity that arise when combined with $D$ and $H$. In addition, we explored standlevel variables especially stand density $(\mathrm{StD})$ as a biological meaningful and potentially more predictive variable than stand age. Finally, we compared the performance of the power-law model with three other models involving $D$ alone, $\mathrm{H}$ alone and their combination with StD. When fitting the models, log transformed biomass data were linearly regressed against the $\log$ transformed values of $D, H, D^{2} H$ and $D H S t D$ as follows:

$\ln (Y)=\ln (\alpha)+\beta(\ln D)+\varepsilon$ Model 1

$\ln (Y)=\ln (\alpha)+\beta\left(\ln D^{2} H\right)+\varepsilon$ Model 2

$\ln (\mathrm{AGB})=\ln (\alpha)+\beta(\ln H)+\varepsilon$ Model 3

$\ln (Y)=\ln (\alpha)+\beta(\ln D H S t D)+\varepsilon$ Model 4

In addition, we explored the relationship between coarse root dry weight (RDW) and AGB using the power-law model specified as follows:

$\ln (\mathrm{RDW})=\ln (\alpha)+\beta(\ln \mathrm{AGB})+\varepsilon$ Model 5

where $Y$ is the biomass component (e.g. foliage, branch, stem, root, etc.) being modelled, $D^{2} H$ is tree volume, and $\varepsilon$ is the error. These models were fitted using ordinary least square regression assuming a power function with multiplicative error structure (Lai et al. 2013; Dong et al. 2016). For estimating biomass components in the arithmetic domain, the equations were back-transformed to give $Y=\alpha X^{\beta} \times \mathrm{CF}$ where $X$ is the single or compound variables, $\alpha X^{\beta}=\exp .(\alpha+\beta(\ln X)$ and $\mathrm{CF}$ is the correction factor calculated from the mean square of error (MSE) as exp.(MSE/2) (Sileshi 2015).

In the absence of measured tree height, the $H$ in model 2 may be estimated using height-diameter (H-D) models. This is a convenient approach because data on tree height are relatively more difficult and time consuming to obtain than $D$. H-D models can also be used to predict missing heights from field measurement of tree diameter. The commonly used H-D models include Chapman-Richard, exponential, Gompertz, hyperbolic, logistic, Michaelis-Menten (saturation growth), monomolecular, power-law, Richard and Weibull functions (Zeide 1993; Huang et al. 2000). The models are also applied to estimate the asymptotic height, which is often used as a measure of tree size (Thomas 1996). In order to determine the appropriate $H-D$ relationship in rubber trees we compared the following models:

Chapman-Richards $H=a(1-\exp (-b D))^{c}$

Exponential $H=a-b(\exp (-c D))$

Gompertz $H=a(\exp (-\exp (b-c D)))$
Hyperbolic models $H=a+\frac{b}{D}$

Logistic $H=\frac{a}{(1+\exp (b-c D))}$

Michaelis-Menten $H=\frac{a D}{b+D}$

Monomolecular $H=a(1-\exp (-b(D-c)))$

Power-law $H=a D^{b}$

Richards function $H=\frac{a}{(1+\exp (b-c D))^{1 / d}}$

Weibull $H=a-b\left(\exp \left(-c D^{d}\right)\right)$

These models were chosen because they are supported by theory and their parameters have biologically meaningful interpretations. For example, in all models except the power-law, the parameter $a$ represents the asymptotic height of trees. Nonlinear regression was used to estimate parameters of all H-D models.

The performance of all these models was compared using the coefficient of determination $\left(R^{2}\right)$, Akaike information criterion (AIC), and root mean square of error (RMSE) (Sileshi 2014). In all cases the small sample approximation of AIC (i.e. AICc) was used for comparing models. In addition, we checked the normality of residuals by plotting the residuals against the predictor values and the Shapiro-Wilk test. Finally, we compared the 95\% confidence intervals $(\mathrm{CI})$ of the slopes to see whether the corresponding model for different age classes is significantly different or not (Sileshi 2014, 2015).

Using the best model developed through the steps described above, biomass stocks in plantations of different ages was estimated by using the following formula:

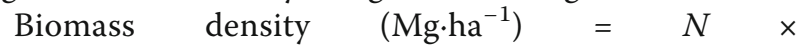
$\left(B_{1}+B_{2}+B_{3}+\ldots+B_{n}\right) / n$

where $N$ is the tree density, $n$ is the number of harvested trees and $B_{i}$ is the AGB stock $(\mathrm{kg})$ of the respective tree.

\section{Results}

\section{Biomass estimation models}

Tree density ranged from 784 trees $\cdot \mathrm{ha}^{-1}$ in $6 \mathrm{yr}$. old plantations to 576 trees $^{-1} \mathrm{~h}^{-1}$ in $34 \mathrm{yr}$. old plantations (Table 1). Stem diameter and tree height also significantly $(P<0.0001)$ varied with stand age. Tree diameter ranged from 11 to $35 \mathrm{~cm}$ in 6 and $34 \mathrm{yr}$. old plantations, respectively (Table 1 ).

A strong non-linear relationship was observed between stem height $(H)$ and diameter at $200 \mathrm{~cm}(D)$ in all the stand ages (Fig. 1; Table 2). Among the H-D models compared, the Michaelis-Menten function had the smallest AIC and RMSE and the largest pseudo $R^{2}$. The second best model was the power-law model, while the worst was the hyperbolic function. The differences in terms of model goodness of fit criteria (pseudo $R^{2}$, AIC and RMSE) among the models except the hyperbolic were marginal (Table 3). However, the 95\% confidence limits of the estimated asymptotic heights reveal significant differences among the models. Some of the models (e.g. Weibull and Richard functions) had four parameters and hence are 
Table 1 Average tree density, stem diameter at $200 \mathrm{~cm}$, height (cm) and aboveground biomass (AGB), coarse root biomass and total biomass stocks estimated using the best model (Model 2) in different ages of rubber plantation in North East India

\begin{tabular}{|c|c|c|c|c|c|c|}
\hline \multirow{2}{*}{$\begin{array}{l}\text { Stand } \\
\text { age (yrs) }\end{array}$} & \multirow{2}{*}{$\begin{array}{l}\text { Density } \\
\left(\text { tree }^{-1} a^{-1}\right)\end{array}$} & \multirow{2}{*}{$\begin{array}{l}\text { Diameter } \\
(\mathrm{cm})\end{array}$} & \multirow{2}{*}{$\begin{array}{l}\text { Height } \\
(\mathrm{cm})\end{array}$} & \multicolumn{3}{|l|}{ Biomass stocks } \\
\hline & & & & AGB $\left(M^{\prime} \cdot h a^{-1}\right)$ & Coarse root $\left({\left.\mathrm{Mg} \cdot h \mathrm{a}^{-1}\right)}\right.$ & Total biomass $\left({\left.\mathrm{Mg} \cdot h \mathrm{~h}^{-1}\right)}^{-1}\right.$ \\
\hline 6 & $784(6)$ & $11.1(1.48)$ & $8.3(0.68)$ & $28.9(18.9)$ & $4.1(1.0)$ & $31.5(18.2)$ \\
\hline 15 & $720(11)$ & $19.9(1.32)$ & $15.2(0.61)$ & $119.4(16.8)$ & $10.3(0.9)$ & $121.4(16.2)$ \\
\hline 27 & $688(11)$ & $19.5(1.48)$ & $16.5(0.68)$ & $116.4(18.9)$ & $10.0(1.0)$ & $118.4(18.2)$ \\
\hline 34 & $576(25)$ & $23.8(1.35)$ & $20.0(0.62)$ & $169.6(17.3)$ & $11.9(1.0)$ & $167.6(16.6)$ \\
\hline All ages & $692(44)$ & $18.9(0.88)$ & $15.3(0.60)$ & $112.0(10.7)$ & $9.3(0.6)$ & $113.0(10.3)$ \\
\hline
\end{tabular}

Values in parentheses are standard errors of means

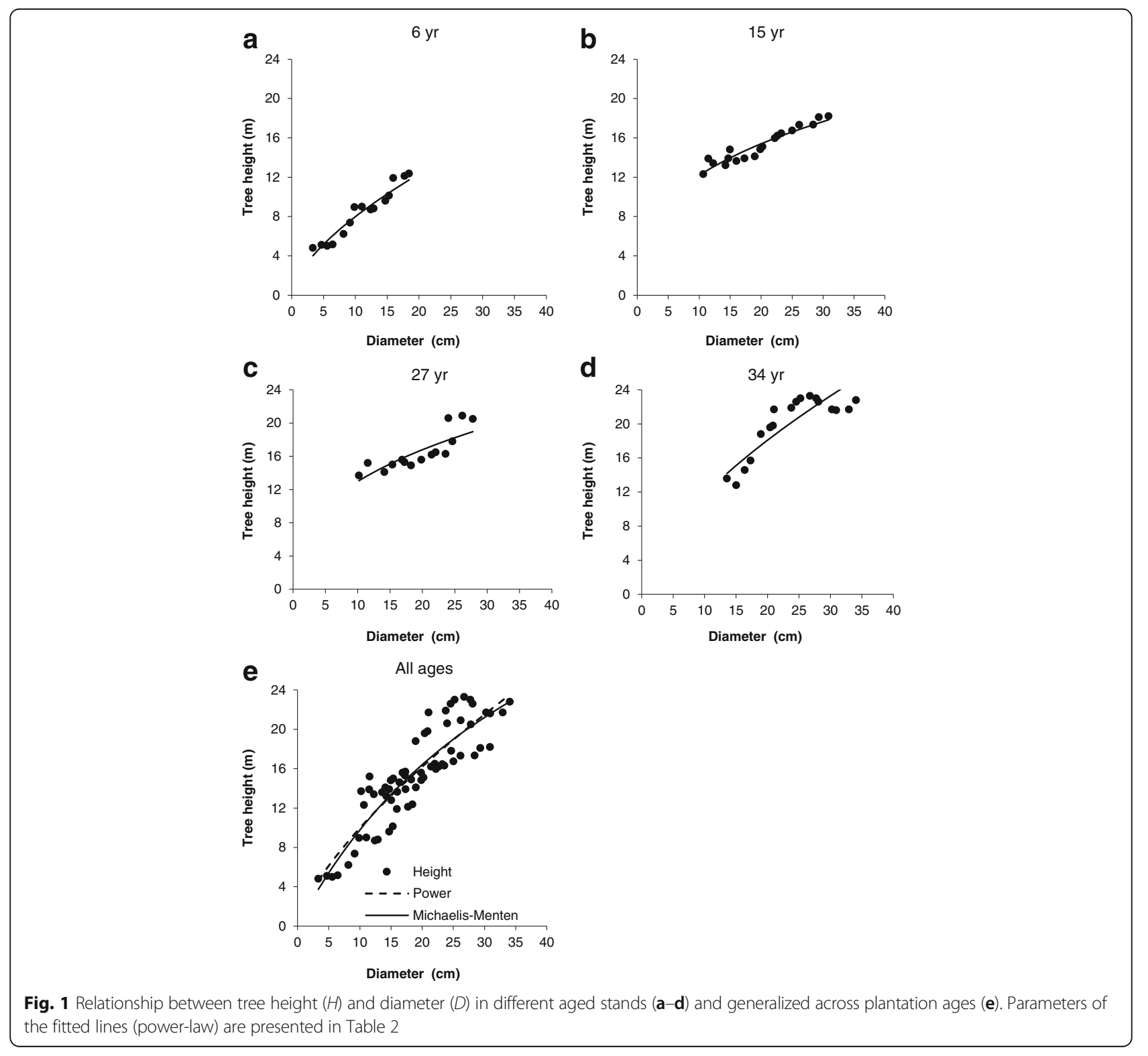


Table 2 Parameter estimates and model fit criteria for ten different height-diameter (H-D) models

\begin{tabular}{lllllllll}
\hline Model & $a$ & $b$ & $c$ & $d$ & AlCc & $R^{2}$ & RMSE & 95\% Cl of asymptotic height \\
\hline Michaelis-Menten & 51.1 & 42.3 & $-^{\mathrm{a}}$ & - & $\mathbf{1 1 2 . 4}$ & $\mathbf{0 . 7 9 5}$ & $\mathbf{2 . 2 4}$ & $33.8-68.5$ \\
Power law & 1.98 & 0.70 & - & - & 114.3 & 0.790 & 2.27 & - \\
Gompertz & 24.9 & 0.84 & 0.09 & - & 114.4 & 0.796 & 2.25 & $20.0-29.8$ \\
Chapman-Richard & 30.0 & 0.04 & 1.07 & - & 114.5 & 0.796 & 2.25 & $13.5-46.5$ \\
Monomolecular & 31.3 & 0.04 & 0.17 & - & 114.5 & 0.796 & 2.25 & $18.2-44.4$ \\
Exponential & 31.3 & 31.52 & 0.04 & - & 114.5 & 0.796 & 2.25 & $18.2-44.4$ \\
Logistic & 23.1 & 1.72 & 0.13 & - & 114.9 & 0.795 & 2.26 & $19.8-26.3$ \\
Weibull & 25.5 & 23.40 & 0.02 & 1.34 & 116.6 & 0.797 & 2.27 & $11.2-39.9$ \\
Richard & 24.8 & -2.12 & 0.09 & 0.05 & 116.8 & 0.796 & 2.27 & $14.0-35.5$ \\
Hyperbolic & 20.9 & -84.9 & - & - & 159.7 & 0.585 & 3.19 & $19.5-22.3$
\end{tabular}

$-{ }^{\mathrm{a}}$ represents that parameter is not applicable

${ }^{\mathrm{b}}$ Indicates that convergence criteria not met

Model fit statistics of the best model are in bold face

complicated or fail to converge. For practical purposes, the following two models were chosen for estimating $H$ in the absence of measured height:

Michaelis-Menten: $H=\frac{51.1 D}{42.3+D}$

Power-law: $H=1.99 D^{0.70}$

Examination of the confidence limit of the slopes of the age-specific models (Table 3 ) indicated that slopes for ages

Table 3 Parameters ${ }^{a}$ and model fit statistics for the age-specific models of aboveground biomass (AGB). For ease of comparing slopes $(\beta)$ the $95 \%$ confidence limits were presented

\begin{tabular}{|c|c|c|c|c|c|c|}
\hline Model & $\begin{array}{l}\text { Stand } \\
\text { age } \\
\text { (yrs) }\end{array}$ & $\begin{array}{l}\text { Intercept } \\
(\ln (a))\end{array}$ & Slope $(\beta)^{b}$ & $\begin{array}{l}\text { Model } \\
R^{2}\end{array}$ & $\begin{array}{l}\text { fit } \\
\text { AIC }\end{array}$ & $\begin{array}{l}\text { criteria } \\
\text { RMSE }\end{array}$ \\
\hline \multirow[t]{5}{*}{1} & 6 & -2.9 & $2.57(2.49-2.65)$ & 0.997 & -70.8 & 0.077 \\
\hline & 15 & -2.01 & $2.25(2.11-2.39)$ & 0.984 & -84.0 & 0.095 \\
\hline & 27 & -0.32 & $1.84(1.53-2.15)$ & 0.909 & -45.5 & 0.717 \\
\hline & 34 & -2.12 & $2.43(2.18-2.68)$ & 0.958 & -64.3 & 0.143 \\
\hline & All ages & -2.83 & $2.60(2.46-2.74)$ & 0.954 & -170.6 & 0.271 \\
\hline \multirow[t]{5}{*}{2} & 6 & -3.49 & $0.97(0.94-1.00)$ & 0.998 & -66.6 & 0.089 \\
\hline & 15 & -3.64 & $0.96(0.90-1.02)$ & 0.980 & -79.4 & 0.107 \\
\hline & 27 & -1.71 & $0.78(0.67-0.89)$ & 0.938 & -51.4 & 0.059 \\
\hline & 34 & -3.08 & $0.93(0.87-0.99)$ & 0.983 & -80.5 & 0.092 \\
\hline & All ages & -3.31 & $0.95(0.91-0.99)$ & 0.976 & -217.1 & 0.192 \\
\hline \multirow[t]{5}{*}{3} & 6 & -4.85 & $3.79(3.22-4.36)$ & 0.93 & -24.2 & 0.365 \\
\hline & 15 & -11.28 & $5.85(4.71-6.99)$ & 0.858 & -42.3 & 0.285 \\
\hline & 27 & -5.53 & $3.79(2.73-4.85)$ & 0.79 & -32.8 & 0.274 \\
\hline & 34 & -4.15 & $3.23(2.63-3.83)$ & 0.876 & -44.8 & 0.246 \\
\hline & All ages & -3.49 & $3.04(2.81-3.27)$ & 0.911 & -126.6 & 0.376 \\
\hline
\end{tabular}

Model fit statistics of the best model for a given plantation age are in bold face

${ }^{a}$ All parameters were significantly different from zero. Therefore $P$ values were not included

${ }^{b}$ Figures in parentheses represent $95 \%$ confidence limits of the slope. Two or more slopes are significantly different from each other only if their confidence limits do not overlap
6 and 34 yr. are not significantly different from the slopes of the models generalized across all age classes. Due to this and the small sample size for individual ages, equations that are generalized across all age classes were developed and tested. Based on the higher $R^{2}$ and lower AIC and RMSE, Model 2 and 4 were found to be more appropriate for AGB, stem, coarse root and total dry weight than Model 1 and 3 (Table 4). On the other hand, the power-law model was more appropriate for foliage and branch biomass. Therefore, the following models were proposed for estimation of AGB, foliage, branch, stem, coarse root $(\mathrm{RDW})$ and total biomass components:

$\mathrm{AGB}=\left(\exp \left(-3.31+0.95\left(\ln D^{2} H\right)\right)\right) \times 1.02$

Foliage $=(\exp (-4.41+1.87(\ln D)) \times 1.25$

Branch $=(\exp (\times 2.76+2.07(\ln D)) \times 1.20$

Stem $=\left(\exp \left(-4.57+1.05\left(\ln D^{2} H\right)\right)\right) \times 1.03$

$\mathrm{RDW}=(\exp (-0.53+0.64(\ln \mathrm{AGB})) \times 1.03$

Total $=\left(\exp \left(-2.84+0.90\left(\ln D^{2} H\right)\right)\right) \times 1.02$

In addition, RDW could be estimated using model 2 as RDW $=\left(\exp \left(-2.64+0.60\left(\ln D^{2} H\right)\right)\right) \times 1.04$. However, in terms of goodness of fit criteria, Model 5 was only slightly better than Model 2 and Model 4 (Table 4).

\section{Variation in tree biomass components}

The measured and estimated biomass components significantly varied with stand age (Fig. 2). However, the measured biomass components were not significantly different from the estimated biomass in all plantation ages. The exception was branch dry weight at 34 yr., where the estimated branch dry weight was higher than the measured dry weight. Measured total aboveground (AGB) dry weight increased from $35.4 \mathrm{~kg} \cdot \mathrm{tree}^{-1}$ in $6 \mathrm{yr}$. plantations to $288.5 \mathrm{~kg} \cdot \operatorname{tree}^{-1}$ in $34 \mathrm{yr}$. old plantations (Fig. 2a). However, using different models the estimated total AGB for all the ages are given in Fig. 3. Measured foliage dry weight increased from $3 \mathrm{~kg} \cdot$ tree $^{-1}$ in $6 \mathrm{yr}$. old plantations to $5 \mathrm{~kg} \cdot \mathrm{tree}^{-1}$ in $34 \mathrm{yr}$. old plantations, but 
Table 4 Parameters and goodness of fit statistics for the various models used in estimating biomass components combining all stand ages

\begin{tabular}{|c|c|c|c|c|c|c|}
\hline Components & Model & Intercept & Slope & $R^{2}$ & $\mathrm{AlCC}$ & RMSE \\
\hline \multirow[t]{4}{*}{$\overline{A G B}$} & 1 & $-2.82(0.21)^{\mathrm{a}}$ & $2.60(0.07)$ & 0.954 & -170.6 & 0.270 \\
\hline & 2 & $-3.31(0.15)$ & $0.95(0.02)$ & 0.977 & -217.1 & 0.192 \\
\hline & 3 & $-3.49(0.32)$ & $3.03(0.12)$ & 0.911 & -126.6 & 0.377 \\
\hline & 4 & $-14.47(0.46)$ & $1.58(0.04)$ & 0.963 & -186.2 & 0.241 \\
\hline \multirow[t]{4}{*}{ Foliage } & 1 & $-4.41(0.51)$ & $1.87(0.18)$ & 0.635 & -49.0 & 0.672 \\
\hline & 2 & $-4.48(0.57)$ & $0.65(0.07)$ & 0.588 & -40.9 & 0.713 \\
\hline & 3 & $-3.91(0.71)$ & $1.82(0.27)$ & 0.418 & -17.8 & 0.847 \\
\hline & 4 & $-11.89(1.41)$ & $1.07(0.12)$ & 0.559 & -36.4 & 0.738 \\
\hline \multirow[t]{4}{*}{ Branches } & 1 & $-2.76(0.46)$ & $2.03(0.16)$ & 0.714 & -62.5 & 0.607 \\
\hline & 2 & $-2.95(0.51)$ & $0.71(0.06)$ & 0.687 & -56.4 & 0.636 \\
\hline & 3 & $-2.60(0.65)$ & $2.11(0.24)$ & 0.543 & -31.1 & 0.767 \\
\hline & 4 & $-11.32(1.25)$ & $1.19(0.10)$ & 0.672 & -53.4 & 0.650 \\
\hline \multirow[t]{4}{*}{ Stem } & 1 & $-3.97(0.27)$ & $2.88(0.09)$ & 0.934 & -131.8 & 0.362 \\
\hline & 2 & $-4.57(0.19)$ & $1.05(0.02)$ & 0.972 & -188.4 & 0.237 \\
\hline & 3 & $-4.95(0.29)$ & $3.45(0.11)$ & 0.941 & -139.4 & 0.342 \\
\hline & 4 & $-17.09(0.50)$ & $1.77(0.04)$ & 0.967 & -176.5 & 0.259 \\
\hline \multirow[t]{5}{*}{ Coarse roots } & 1 & $-2.4(0.23)$ & $1.7(0.08)$ & 0.871 & -155.1 & 0.305 \\
\hline & 2 & $-2.64(0.23)$ & $0.60(0.03)$ & 0.883 & -161.9 & 0.290 \\
\hline & 3 & $-2.69(0.32)$ & $1.91(0.12)$ & 0.802 & -126.7 & 0.375 \\
\hline & 4 & $-9.84(0.56)$ & $1.02(0.05)$ & 0.881 & -160.9 & 0.292 \\
\hline & 5 & $-0.53(0.12)$ & $0.64(0.03)$ & 0.905 & -175.4 & 0.261 \\
\hline \multirow[t]{4}{*}{ Total biomass } & 1 & $-2.38(0.20)$ & $2.49(0.07)$ & 0.954 & -176.7 & 0.259 \\
\hline & 2 & $-2.84(0.15)$ & $0.90(0.02)$ & 0.976 & -221.2 & 0.184 \\
\hline & 3 & $-3.00(0.31)$ & $2.89(0.11)$ & 0.908 & -130.9 & 0.365 \\
\hline & 4 & $-13.50(0.45)$ & $1.51(0.04)$ & 0.963 & -191.1 & 0.232 \\
\hline
\end{tabular}

Goodness of fit statistics of the best model is in bold face

${ }^{\text {a }}$ igires in parenthesis are standard errors of estimates

foliage biomass in 6 yr. plantations did not significantly differ from those in 27 yr. plantations (Fig. 2b). Measured branch dry weight increased from $11 \mathrm{~kg} \cdot \mathrm{tree}^{-1}$ in 6 yr. plantations to $43 \mathrm{~kg} \cdot \mathrm{tree}^{-1}$ in $27 \mathrm{yr}$. old plantations and then decreased to $35 \mathrm{~kg} \cdot$ tree $^{-1}$ in $34 \mathrm{yr}$. old plantations (Fig. 2c). Measured stem dry weight increased from $21 \mathrm{~kg} \cdot$ tree $^{-1}$ in $6 \mathrm{yr}$. plantations to $249 \mathrm{~kg} \cdot$ tree $^{-1}$ in $34 \mathrm{yr}$. old plantations (Fig. 2d). Similarly, coarse root dry weight increased from $5.4 \mathrm{~kg} \cdot \mathrm{tree}^{-1}$ in $6 \mathrm{yr}$. plantations to $19 \mathrm{~kg} \cdot \mathrm{tree}^{-1}$ in $34 \mathrm{yr}$. old plantations (Fig. 2e). The coarse root biomass estimated using the three models also did not significantly differ (Fig. 4). However, estimating coarse root biomass from AGB (Model 5) was superior to other models in terms of goodness of fit criteria (Table 4) and normality of residuals (Fig. 4c). Total dry weight of all components increased from $40 \mathrm{~kg}$.tree ${ }^{-1}$ in 6 yr. old plantations to $307 \mathrm{~kg} \cdot \mathrm{tree}^{-1}$ in $34 \mathrm{yr}$. old plantations (Fig. 2e). In terms of the mean absolute percentage error (MAPE), AGB, total biomass and stem biomass were estimated with less error (MAPE <20\%) compared to coarse root dry weight (MAPE $=21 \%$ ). Branch dry weight $(\mathrm{MAPE}=80 \%)$ and foliage dry weight $(\mathrm{MAPE}=83 \%)$ were poorly estimated. Foliage dry weight was underestimated in 6 yr. old plantations compared to the measured (Fig. 2b), while stem dry weight was severely overestimated in $34 \mathrm{yr}$. old plantations.

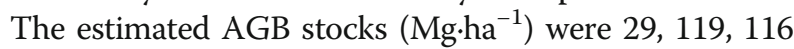
and $169 \mathrm{Mg} \cdot \mathrm{ha}^{-1}$ for 6, 15, 27 and 34 yr. old plantations, respectively (Table 1 ). The coarse root biomass was estimated at $4 \mathrm{Mg} \cdot \mathrm{ha}^{-1}$ for $6 \mathrm{yr}$. old plantations and $12 \mathrm{Mg} \cdot \mathrm{ha}$

${ }^{-1}$ for 34 yr. old plantations. Similarly, total biomass (ex-

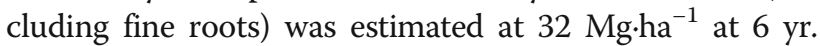

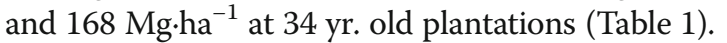

\section{Discussion}

The average stand density of rubber plantations declined from 784 trees $^{-1} \mathrm{ha}^{-1}$ in $6 \mathrm{yr}$. old plantations to 576 in 34 yr. old plantations. Since, a common plant spacing of 

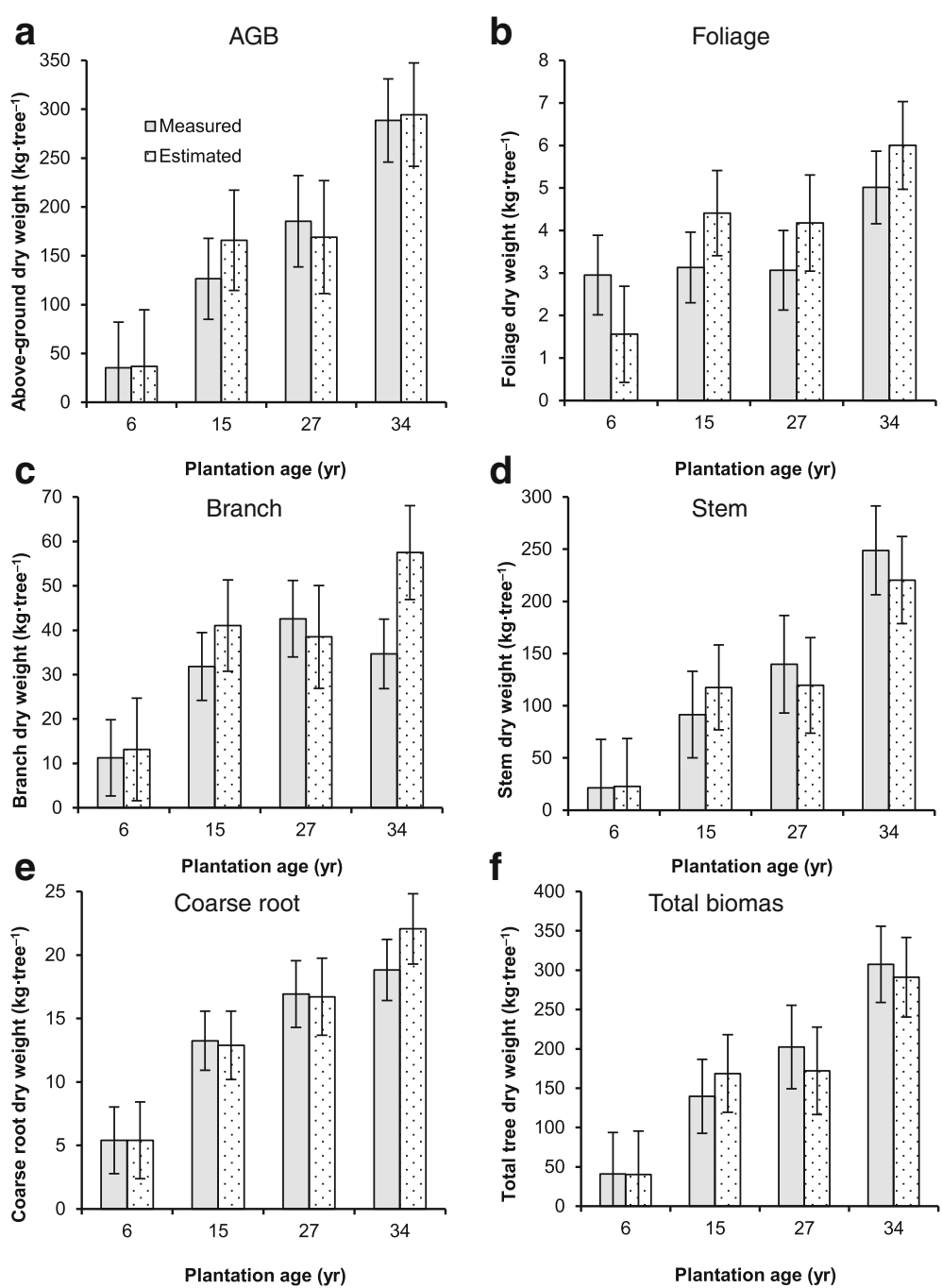

Fig. 2 Variation in measured and estimated tree biomass components with plantation age. Parameters of the best model in Table 4 were used for estimating the specific biomass component. The measured and estimated biomass components are deemed significantly different from each other only if their confidence limits do not overlap

$3 \mathrm{~m} \times 4 \mathrm{~m}$ was maintained during the initial plantation stage, the results indicate that the number of trees in plantation decreased by about $26 \%$ with the increase in stand age. This implies that plantation density reduced at $0.95 \%$ per annum, and this is comparable with the $1.5 \%$ reduction reported from Sri Lanka (Munasinghe et al. 2014). This is consistent with predictions of Yoda's law (Yoda et al. 1963) and the stand density rule of Reineke (Reineke 1933).

From the H-D models it is evident that the MichaelisMenten and power-law models are adequate, while the gain in explanatory power from the other models was minimal. Therefore, in the absence of measured tree height, $H$ estimated using the Michaelis-Menten function can be used to estimate tree volume. The results also suggest that AGB can be estimated more accurately using models consisting of compound variables of $D$ and
$H$. The power-law model (Model 1) was slightly poorer in terms of goodness of fit criteria. The poor performance of the power-law model could be attributed to data truncation (Sileshi 2015), which is evident in Fig. 1. Data truncation can occurs either due to sampling that only includes those individuals whose size lies within a certain interval or when equations are fitted to a restricted segment of the size range. Data are said to be left truncated when the lower segment of the population has been left out, whereas right-truncation results from leaving out the upper segment. Sileshi (2015) has demonstrated that the allometry exponent can be highly biased when the power-law equation is fitted to a restricted segment of the size range or different life stages of a species. In the different plantation ages except at $6 \mathrm{yr}$., data are evidently left truncated, i.e. the lower segment of the 

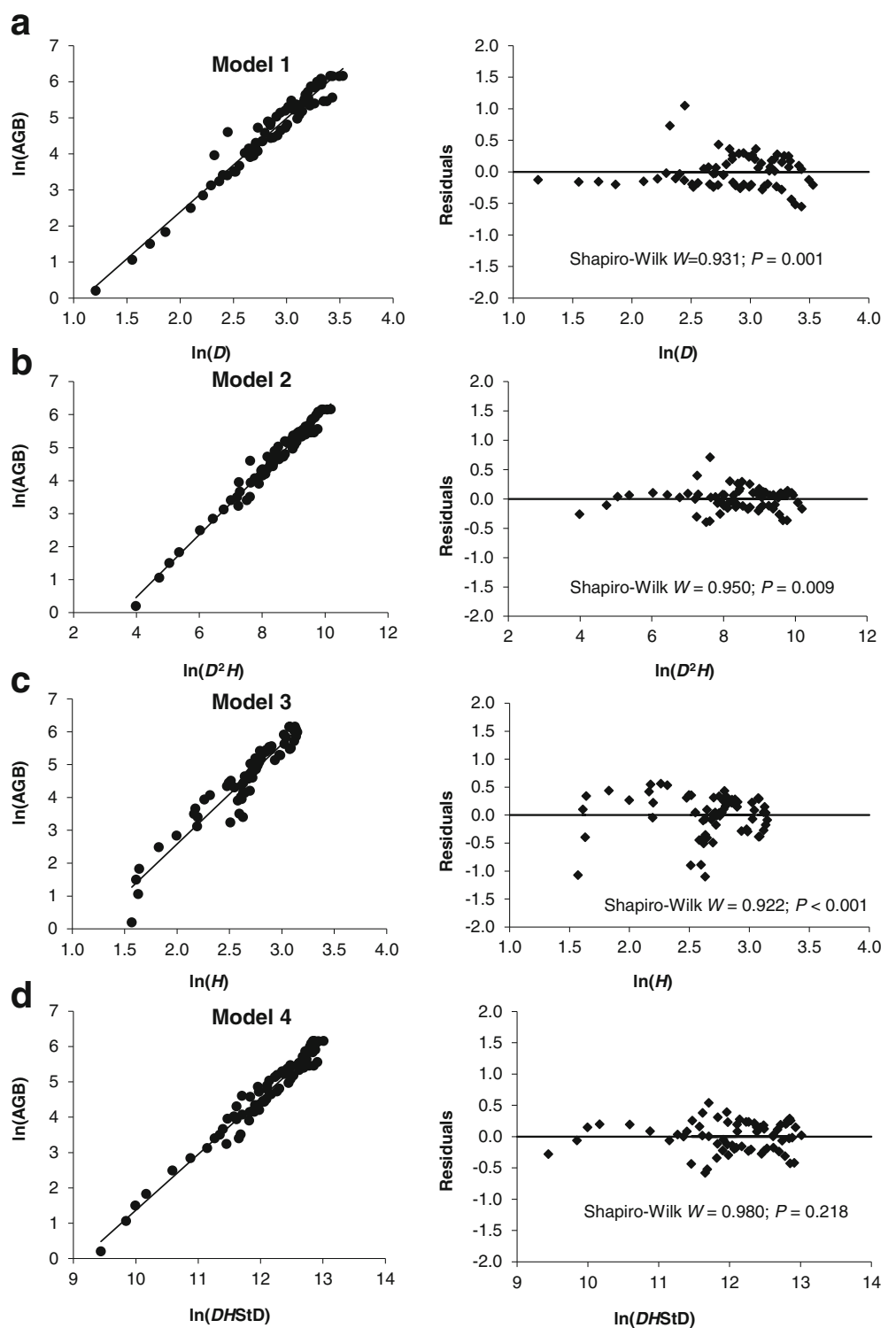

Fig. 3 Fitted lines of the models used for above-ground biomass (AGB) and plots of the residuals against observed values for rubber plantations of all ages. Parameters of the fitted lines are presented in Table 4

population has been left out. Left-truncation of data tends to raise the allometry intercept and as a result shrink the slope (Sileshi 2015). On the other hand, Model 2 slopes did not significantly differ from each other except at plantation age of 15 . As the models for all ages were developed from a larger dataset, they may be less sensitive to change in age and hence may be used for future AGB estimations of 6, 27 and 34 yrs. old plantations.

Among the models compared, the model that contains tree volume had higher predictive power for AGB and total tree biomass. This is consistent with the general observation that AGB increases with bole volume in woody species (Chave et al. 2005). Although the use of fewer explanatory variables are recommended for ease in model application and validation (Sileshi 2014), in the present study $D$ and $H$ were directly measured and therefore could be applied for biomass estimation.

In this study the focus was on the aboveground living biomass and coarse roots (excluding fine roots) of trees since these components account for the largest percentage of the sequestered carbon within a forest ecosystem (Kongsager et al. 2013). Root biomass is difficult to measure in most conditions. Therefore, we recommend direct estimation of coarse root biomass from measured AGB assuming a power-law relationship between root biomass and AGB (i.e. Model 5).This assumption is reasonable because allometry theory and empirical observations have demonstrated near-isometric relationships 

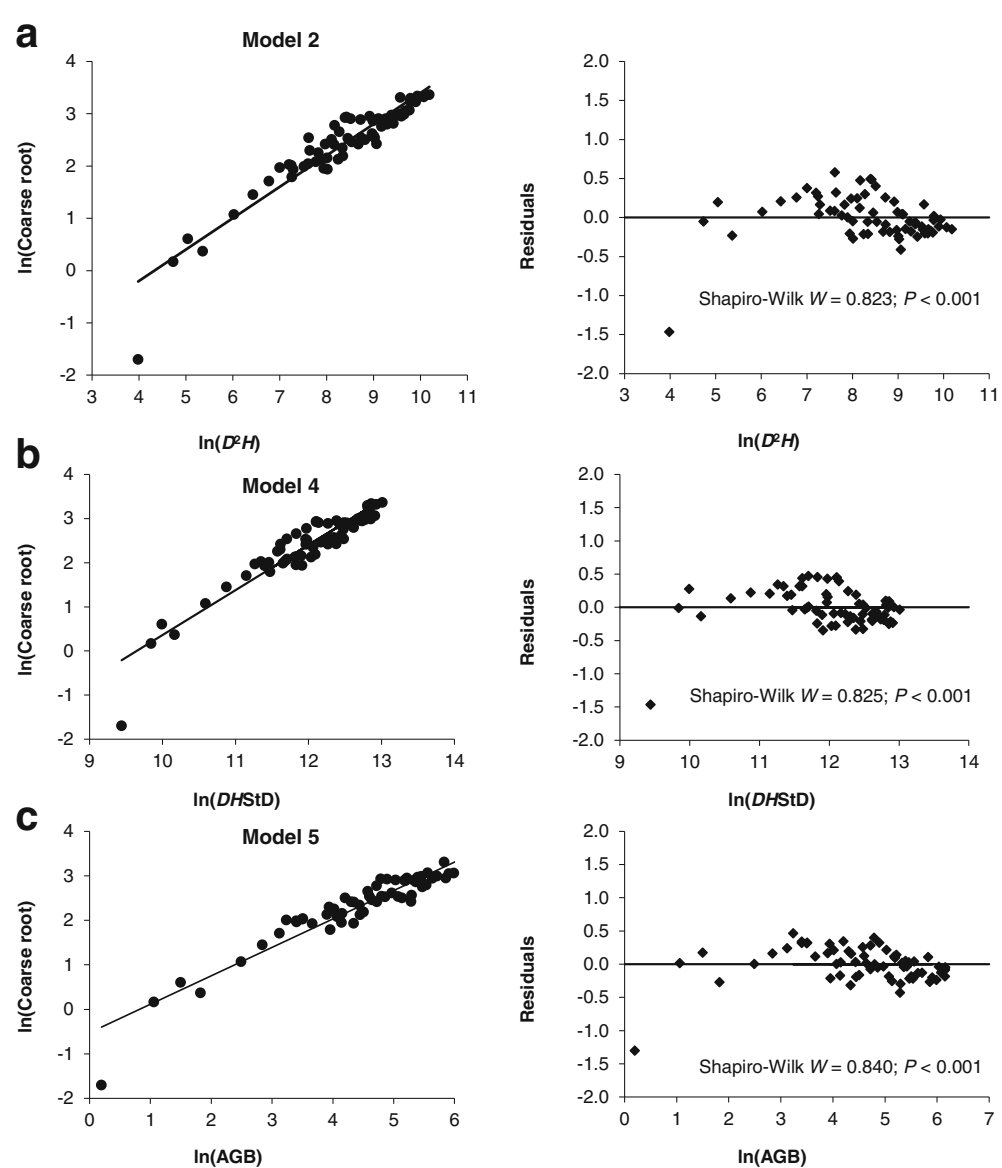

Fig. 4 Fitted lines of the models used for coarse root dry weight (RDW) and plots of the residuals against observed values for rubber plantations of all ages. Parameters of the fitted lines are presented in Table 4

between aboveground and belowground biomass of trees (Cheng and Niklas 2007; Hui et al. 2014).

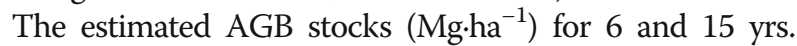
old rubber trees are comparable with values (56 and $248 \mathrm{~kg} \cdot \mathrm{tree}^{-1}$ ) reported from Brazil (Maggiotto et al. 2014). AGB estimates for 27 and 34 yr. old plantations are 25 and $50 \%$ lower than the estimated total biomass for 25 and 38 yr. old rubber plantations from China (Tang et al. 2009; Yang et al. 2014). These differences could be related to differences in planting density, growth habitat and management practices (Yang et al. 2014). Moreover, total biomass stocks of 5 to 40 yrs. old rubber plantations from the same

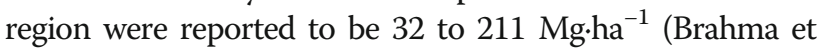
al. 2016). Similar to the present study the AGB stock in rubber plantations increased with increase in plantation age (Chaudhuri et al. 1995; Dey et al. 1996; Yang et al. 2005; Tang et al. 2009; Corpuz et al. 2014; Maggiotto et al. 2014; Brahma et al. 2016).

\section{Conclusions}

It is concluded that models involving tree volume are more appropriate for regional level biomass estimation than simple models for individual stands. We recommend that the power-law model should not be used for estimation of AGB of plantations at different growth stages because power-law parameters can be biased due to data truncation. Our study suggests that the model generalizing all the ages can be used irrespective of the age of the stand. In the absence of measured height, we recommend the Michaelis-Menten model for estimating height. One of the limitations of this study is the relatively small sample size for developing age-specific models. Another limitation is our inability to sample total belowground biomass due to resource constraints to collect fine roots. We recommend that future studies tackle these issues.

\section{Additional file}

Additional file 1: Dataset for biomass stock of rubber plantations. (XLS $34 \mathrm{~kb}$ )

\section{Acknowledgements}

We gratefully acknowledge the owners (Mr. Goutam Nandi and Mr. Kabir Uddin Ahmed) of the Hevea plantations for allowing us to harvest required 
number of trees from their plantations. We also sincerely thank DST, GOI for funding (DST/IS-STAC/CO2-SR-224/14(C)-AICP-AFOLU-1)

\section{Availability of data and materials}

Raw data is available in the Additional file 1.

\section{Authors' contributions}

$\mathrm{BB}$ and $\mathrm{AJN}$ formulated the idea and design sampling method. AJN and AKD supervised the study. BB collected field data. BB and SWG performed data analyses. All authors reviewed and revised the manuscript. All authors read and approved the final manuscript.

\section{Competing interests}

The authors declare that they have no competing interests.

\section{Author details}

'Department of Ecology and Environmental Science, Assam University, Silchar, Assam 788011, India. ${ }^{2}$ Plot 1244 Ibex Hill, Lusaka, Zambia.

Received: 11 May 2017 Accepted: 8 August 2017

Published online: 24 August 2017

\section{References}

Brahma B, Nath AJ, Das AK (2016) Managing rubber plantations for advancing climate change mitigation strategy. Curr Sci 110(10):2015-2019

Brown S (1997) Estimating biomass and biomass change in tropical forest. Food and Agriculture Organization of the United Nations, p 55

Brown S, Schroeder PE (1999) Spatial patterns of aboveground production and mortality of woody biomass for eastern US forests. Ecol Appl 9:968-980

Chaudhuri D, Vinod KK, Potty SN, Sethuraj MR, Pothen J, Reddy Y (1995) Estimation of biomass in Hevea clones by regression method: relation between girth and biomass. Ind J Nat Rubber Res 8(2):113-116

Chave J, Andalo C, Brown S, Cairns MA, Chambers JQ, Eamus D, Fölster H, Fromard F, Higuchi N, Kira T, Lescure JP, Nelson BW, Ogawa H, Puig H, Riéra B, Yamakura T (2005) Tree allometry and improved estimation of carbon stocks and balance in tropical forests. Oecologia 145:87-99

Chave J, Riera B, Dubois MA (2001) Estimation of biomass in a neotropical forest of French Guiana: spatial and temporal variability. J Trop Ecol 17:79-96

Cheng D, Niklas K (2007) Above- and below-ground biomass relationships across 1543 forested communities. Ann Bot 99:95-102

Corpuz OS, Abas EL, Salibio FC (2014) Potential carbon storage of rubber plantations. Ind J Pharm Biol Res 2:73-82

De Oliveira AA, Mori SA (1999) A central Amazonian terra firm forest I. High tree species richness on poor soils. Biodivers Conserv 8:1219-1244

Dey SK, Chaudhuri D, Vinod KK, Pothen J, Sethuraj MR (1996) Estimation of biomass in Hevea clones by regression method: 2. Relation of girth and biomass for mature trees of clone RRIM 600. Ind J Nat Rubb Res 9:40-43

Dong L, Zhang L, Li F (2016) Developing two additive biomass equations for three coniferous plantation species in Northeast China. Forests. doi:10.3390/ f7070136

Fatemi FR, Yanai RD, Hamburg SP, Vadeboncoeur MA, Arthur MA, Briggs RD, Levine CR (2011) Allometric equations for young northern hardwoods: the importance of age-specific equations for estimating aboveground biomass. Can J For Res 891:881-891

Fox J, Vogler JB, Sen OL, Giambelluca TW, Ziegler AD (2012) Simulating land-cover change in montane mainland Southeast Asia. Environ Manag 49:968-979

Houghton RA, Lawrence KL, Hackler JL, Brown S (2001) The spatial distribution of forest biomass in the Brazilian Amazon: a comparison of estimates. Glob Chang Biol 7:731-746

Huang S, Price D, Titus SJ (2000) Development of ecoregion-based heightdiameter models for white spruce in boreal forests. For Ecol Manag 129: $125-14$

Hui D, Wang J, Shen W, Le X, Ganter P, Ren H (2014) Near isometric biomass partitioning in forest ecosystems of China. PLoS One 9:e86550

Husch B, Beers TW, Kershaw JA (2003) Forest Mensuration, 4th edn. Wiley, Hoboken, pp 85-86

Kongsager R, Napier J, Mertz O (2013) The carbon sequestration potential of tree crop plantations. Mitig Adapt Strateg Glob Chang 18:1197-1213

Lai X, Li F, Leung K (2013) A Monte Carlo study of the effects of common method variance on significance testing and parameter bias in hierarchical linear modelling. Organizat Res Method 16:243-269. doi:10.1177/ 1094428112469667

Maggiotto SR, Oliveira D, Marur CJ, Stivari SMS, Monique L, Wangher-Riddle C (2014) Potential carbon sequestration in rubber tree plantations in the northwestern region of the Paraná state, Brazil. Acta Scient 36:239-245

Munasinghe ES, Rodrigo VHL, Gunawardena UADP (2014) Modus operandi in assessing biomass and carbon in rubber plantations under varying climatic conditions. Exp Agric 50:40-58

Regional Agricultural Research Institute (2013) Agromet advisory service, Karimganj

Reineke LH (1933) Perfecting a stand-density index for even-aged forests. J Agric Res 46:627-638

Shepashenko D, Shvidenko A, Nilsson S (1998) Phytomass (live biomass) and carbon of Siberian forests. Biomass Bioenergy 14:21-31

Sileshi GW (2014) A critical review of forest biomass estimation models, common mistakes and corrective measures. For Ecol Manag 329:237-254

Sileshi GW (2015) The fallacy of retification and misinterpretation of the allometry exponent. doi: 10.13140/RG.2.1.2636.9768

Tang JW, Pang JP, Chen MY, Guo XM, Zeng R (2009) Biomass and its estimation model of rubber plantations in Xishuangbanna, Southwest China. Chin J Ecol 28:1942-1948

Ter-Mikaelian MT, Korzukhin MD (1997) Biomass equation for sixty-five north American tree species. Fore Ecol Manage 97:1-24

The Rubber Board (2013) Indian rubber statistics 2013, vol 36. Rubber Board, Kottayam

Thomas SC (1996) Asymptotic height as a predictor of growth and allometric characteristics in Malaysian rain forest trees. Am J Bot 83:556-566

USDA (1998) Keys to soil taxonomy. In: USDA Handbook, 8th edn. Soil Survey Staff, Washington, DC

Yang JC, Huang JH, Tang JW, Pan QM, Han XG (2005) Carbon sequestration in rubber tree plantations established on former arable lands in Xishuangbanna, SW China. Acta Phytoecol Sina 29:296-303

Yang X, Blagodatskiy S, Cadisch G, Chu XJ (2014) Carbon storage potential of rubber plantations of different age and elevation in Xishuangbanna. Bridging the gap between increasing knowledge and decreasing resources. Tropentag, Prague, pp 17-19

Yoda K, Kira T, Ogawa H, Hozumi K (1963) Self-thinning in overcrowded pure stands under cultivated and natural conditions. J Biol 14:107-129

Zeide B (1993) Analysis of growth equations. For Sci 39:594-616

\section{Submit your manuscript to a SpringerOpen ${ }^{\circ}$ journal and benefit from:}

- Convenient online submission

Rigorous peer review

- Open access: articles freely available online

- High visibility within the field

- Retaining the copyright to your article

Submit your next manuscript at $>$ springeropen.com 